F. med. Genet. (1964). I, II2.

\title{
Cranio-facial Dysostosis and Malformations of Feet*⿳亠丷厂巾
}

\author{
T. J. S. PATTERSON and A. C. STEVENSON \\ From the Department of Plastic Surgery, The Churchill Hospital, Oxford, and The Medical Research Council, Popula- \\ tion Genetics Research Unit, Oxford
}

In I96I a first-born boy aged I8 months was referred to the Plastic Surgery Department of the Churchill Hospital, Oxford, with a left split foot (outline radiographic appearances are shown in Fig. I). No other anomaly was then, or has subsequently been, detected. The parents were not related and the only relevant family history was that the father had abnormalities of the feet. A second female child, normal in every way, was born to the parents in October 1962.

When he was seen the father was found to have severe bilateral malformation of feet. Outline of the radiographic appearances is shown in Fig. 2. Three small toes in the right foot had been amputated in infancy. In addition, it was noted that he had marked micrognathia and asymmetry of the mandible, a high arched palate, and crowded teeth with malocclusion. His eyes had no anti-mongoloid slant, nor was there any evidence of eyelid or other colobomata, or of any other abnormality. His ears were rather long, tapering to disproportionately small lobules. The profile appearance of the face is shown in Fig. 3.

The father had always been very deaf and he wore a hearing aid in his left ear. The right external auditory meatus ended blindly and the left narrowed progressively to a pinhole orifice. Audiometry showed near total loss of perception of air-conducted sound in the right ear. However, there was only between 25 and $50 \%$ loss of perception on bone conduction over a range between frequencies of 250 and 2,000 . In the left ear perception of bone-conducted sound was similar or rather better, but there was considerable perception of air-conducted sound, the loss of acuity relative to average for his age being about $50 \%$ over a range of 250 to 2,000 . It may be surmised from these findings that there is not very much malformation of the middle and inner ear on either side. No other anomalies were detected and in particular there was no evidence of pits or fistulae suggestive of failure of fusion along the line of the first branchial arch. Re-examination of the son at $3 \frac{1}{2}$ years confirmed the normal facio-mandibular and dental configuration and normal external auditory meati, ear-drums, and hearing.

The disorder in the father and son presumably

* Received October 28, 1963. represents varying expression of one of these mutations, usually showing irregular manifestation in the $\vec{\sim}$ heterozygote, which determine the range of the mandi- ? bulo-facial dysostoses which are sometimes accompanied $\vec{N}$ by malformations of the extremities. Examination of chromosomes from white blood cells of the father showed no abnormality.

\section{Discussion}

Franceschetti and Klein (1949) have reviewed $\frac{}{3}$ in detail the preceding published material on mandi- $\mathbb{\Phi}$ bulo-facial dysostosis, and in a subsequent paper $\overrightarrow{\mathscr{A}}$ (Franceschetti, Klein, and Brocher, 1959) have $\odot$ attempted to classify the range and type into complete, incomplete, abortive, unilateral, and 'atypical' forms. All the cases reviewed, however, had marked eye signs. They list anti-mongoloid slant of the eyes, colobomata in the outer portion of the lower $\stackrel{2}{\circ}$ lids, malformations of the external ear and oc- ${ }^{\circ}$. casionally of the inner and middle ear, macros- $\overrightarrow{\vec{O}}$ tomia, abnormal position and occlusion of teeth, 3 and blind fistulae in positions appropriate to origin from the first branchial cleft as the most characteristic signs, with other skeletal manifestations exceptionally occurring. Franceschetti and Klein regard the original descriptions of Berry (1889) $\frac{\dot{0}}{3}$ and of Collins (1900) of these syndromes as of 'abortive' cases. The term Treacher Collins syn- of drome is usually given in the United Kingdom and America and the Franceschetti-Klein syn- o drome in continental Europe.

Malformations of the extremities have been described in association with such syndromes by a number of authors. Franceschetti and Klein (1949) o record one girl with dysplasia of thumbs and radio- N ulnar synostosis. Straith and Lewis (1949) report స్ట a mother and all four children with eye and facial 0 appearances typical of these syndromes: in ad- 6 dition they all had abnormally long second meta- $\stackrel{\complement}{\Phi}$ tarsal bones. O'Connor and Conway (1950) include $\stackrel{\mathcal{D}}{+}$ in their series a 'sporadic' case in a male child with $T$ typical eye and facio-mandibular changes, who 

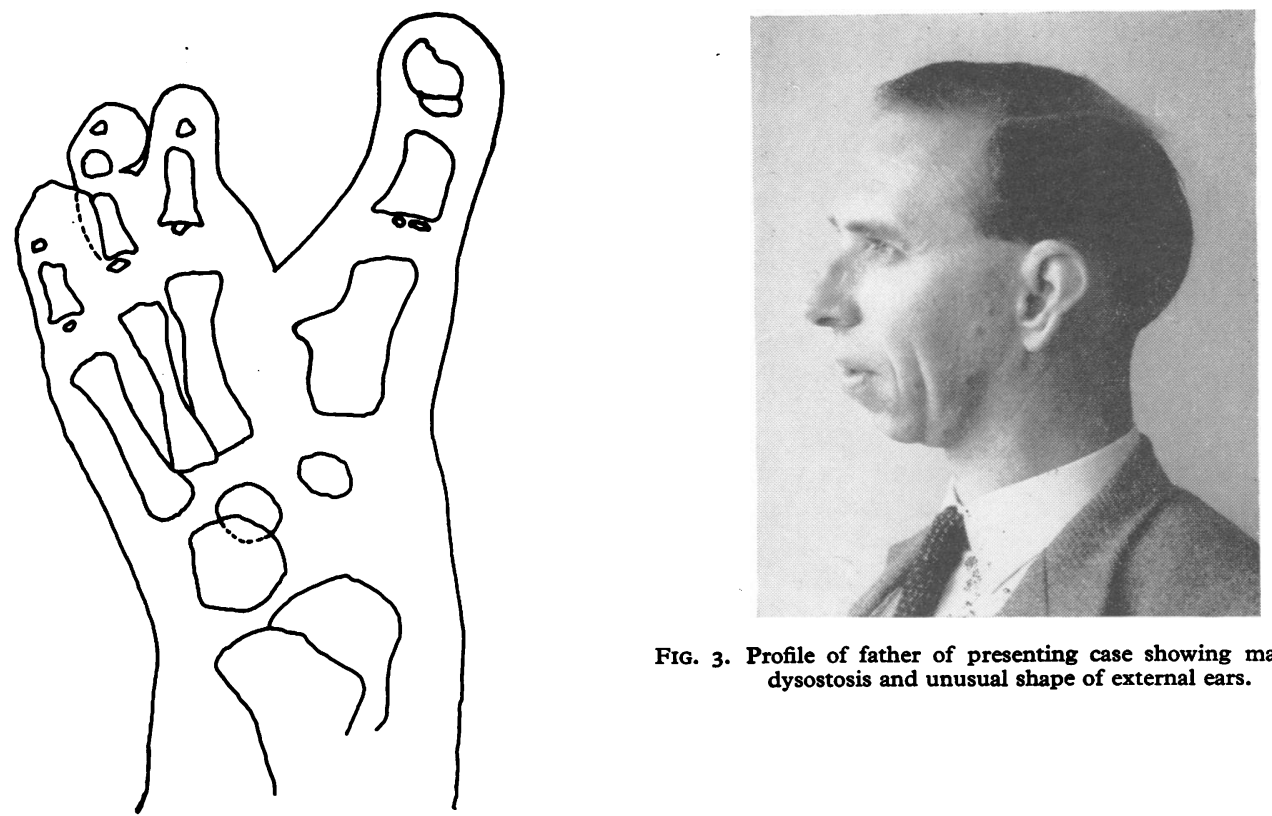

Frg. 3. Profile of father of presenting case showing mandibular dysostosis and unusual shape of external ears.

FIG. I. Outline of radiograph of foot of presenting case-the only anomaly found.
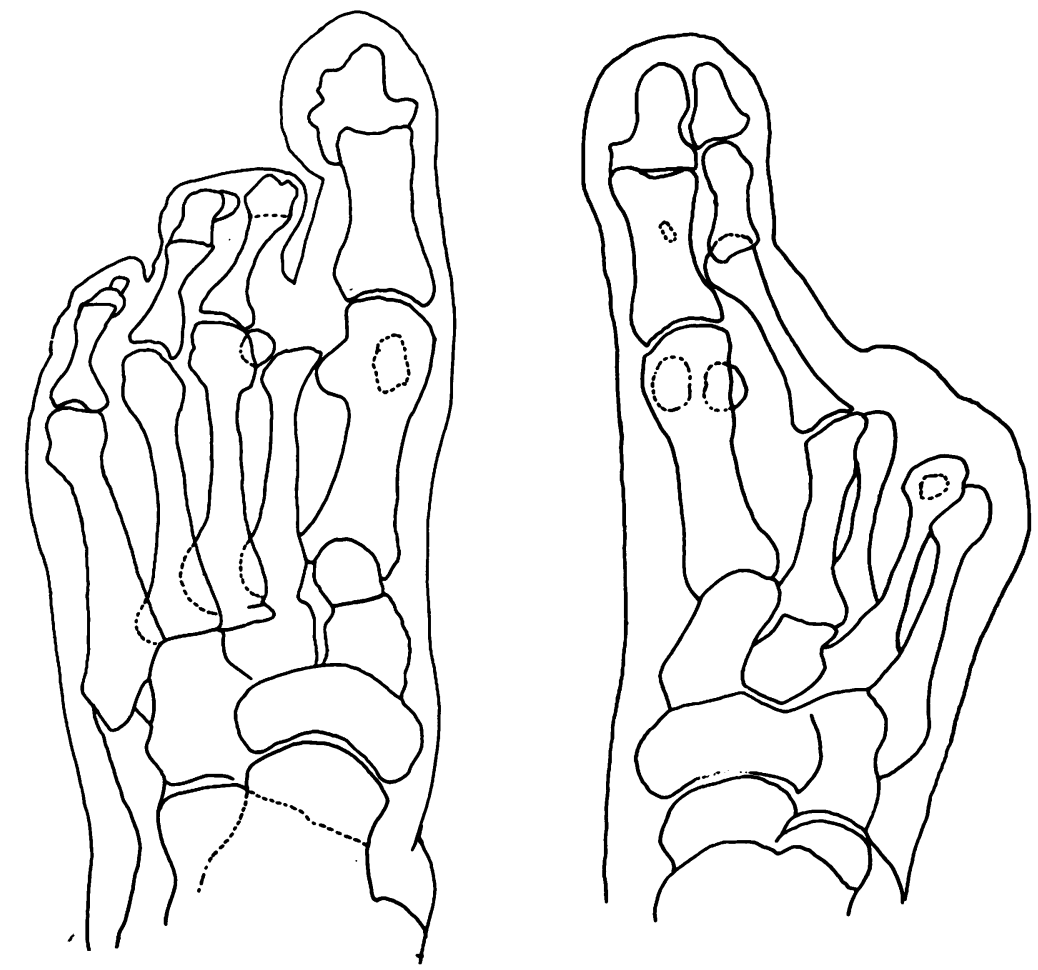

FIG. 2. Outline of radiographs of feet of father of presenting case-three small toes on the right foot had been amputated in infancy. 
had 'bilateral hand and forearm deformities'. Briggs (1953) mentions a boy of ro years with 'mandibulo-facial dysostosis' who had webbed second and third toes in both feet. Judging by photography there was no anti-mongoloid slant in this case though the mandibular aplasia was marked. Another case was described by Harrison (I95I) where the facial agenesis was unilateral (left) and associated with a rudimentary left ear. Both hands showed brachydactyly and clinodactyly, the middle phalanges of the fingers being in varying degrees short with the distal articular surfaces tilted towards the mid-line of the hand. Franceschetti et al. (1959) quote an instance of the syndrome with associated hand deformities as described in a thesis by Ressonica (1950).

Recently Wildervanck (1960) has described two brothers born to unrelated parents with ectrodactyly-type malformations of hands and feet. There were no cranio-facial malformations but the brothers both had severe deafness necessitating education in a school for the deaf. No others similarly deaf or malformed were known in the family. The ear-drums of the boys were normal, and the author classifies the deafness as perceptive though there is no mention in the paper of comparison of acuity with air and bone conduction.

It is clear, therefore, that there is a variety of malformations of external, middle, and possibly inner ear, which may be associated with fusions and ectrodactyly-type anomalies of the extremities. As in the case of families with ectrodactyly alone the extremity anomalies may be of hands, feet, or both, but the distribution is rather constant within families.

The family reported is of particular interest in two ways. First, the father has external ear, meatal, and possible middle ear deformities, associated with facial malformations which affect almost entirely the mandible, sparing the malar bones and the eyes, and has the malformations of the feet described. The son had one foot only affected and the cranio-facio-mandibular appearance is normal. The second point of interest is the way in which attention was called to the family, namely, a young child with a not too uncommon type of foot malformation with nothing to suggest that the anomaly represented the minimal manifestation of a pleiotropic gene.

\section{Summary}

An account is given of a father and son who $\vec{\sigma}$ appear to demonstrate extremes of a manifestation of a mutation determining one of the range of generalized syndromes affecting the face and $\vec{\sim}$ extremities. The son showed only malformation of one foot, whereas the father in addition to bila- $\vec{N}$ teral foot anomalies showed micrognathia, ir- 은 regular dentition, and atresia of the external audi- $工$ tory canals determining conduction deafness.

\section{REFBRENCES}

Berry, G. A. (1889). Note on a congenital defect (? coloboma) of the lower lid. Roy. Lond. ophthal. Hosp. Rep., 12, 255.

Briggs, A. H. (1953). Mandibulo-facial dysostosis. Brit. $\mathscr{F}$. Ophthal., $\overrightarrow{\mid c}$ 37, 171 .

Collins, E. Treacher (1900). Case with symmetrical congenital notches in the outer part of each lower lid and defective development of the malar bones. Trans. ophthal. Soc. U.K., 20, 190.

Franceschetti, A., and Klein, D. (1949). The Mandibulo-facial Dysostosis: A New Hereditary Syndrome. Munksgaard, Copenhagen.

- - , and Brocher, J. E. W. (1959). La dysostose mandibulo- 气̊ faciale dans le cadre des syndromes du premier arc branchial. Schweiz. med. Wschr., 89, 478.

Harrison, S. H. (I95I). Treacher Collins syndrome. Brit. f. plast. $\overline{\bar{O}}$ Surg., 3, 282.

O'Connor, G. B., and Conway, M. E. (1950). Treacher Collins syndrome (dysostosis mandibulo-facialis). Plast. reconstr. Surg., $5,419$.

Ressonica, G. (1952). Dissertation, University of Zurich.

Straith, C. L., and Lewis, J. R. (1949). Associated congenital defects of the ears, eyelids and malar bones (Treacher Collins syndrome). Plast. reconstr. Surg., 4, 204.

Wildervanck, L. S. (1960). Dysostosis mandibulo-facialis (Franceschetti-Zwahlen) in four generations. Acta Genet. med. (Roma), 9, 447 . 